\title{
DIMENSIÓN MÍTICA DEL INDIGENISMO EN MIGUEL ANGEL ASTURIAS
}

\author{
Giuseppe Bellini
}

El problema del indígena ha dominado la sensibilidad de Miguel Angel Asturias desde el comienzo de su actividad creadora. En esta actividad incluyo, entre los documentos escritos que nos lo atestiguan, sus tesis para el grado de abogado, presentada en 1923 en la Facultad de Derecho de la Universidad de San Carlos, El problema social del indio ${ }^{1}$.

El reeditar la obrita ${ }^{2}$, como documento de la sensibilidad asturiana más bien, Claude Couffon advertía que el lector actual tendría «la oportunidad de interrogarse» sobre ella, pero la interpretaba por lo que era, «un grito de alarma destinado a despertar las conciencias adormecidas de las autoridades del país $[\ldots]{ }^{3}$. Sólo que las conciencias no despertaron, como se queja el propio Asturias, en la «Advertencia» a la edición del hispanista francés, a los cincuenta años de la elaboración de su tesis.

La situación puede resumirse en el lapidario juicio: «Nada se ha hecho hasta ahora de efectivo [...]» ${ }^{4}$.

No iremos buscando fundamentos ideológicos, ni científicos, en la primera postura de Asturias. No existen, ni existirán después. De cierto hay un influjo de lecturas de La raza cosmica, del mexicano José Vasconcelos; sabemos que fue él quien animó al estudiante a continuar su trabajo ${ }^{5}$. Su tesis, sin embargo, es más bien una reacción humanitaria, la protesta contra una situación que llamaba dramáticamente la atención. Y en esto consiste su mérito.

1 Asturias presentó su tesis en diciembre de 1923 y la editó en el mismo mes, en la Ciudad de Guatemala, Tipografía Sánchez \& De Guise, con el título Sociología guatemalteca. El problema social del indio, dedicándola a sus padres.

2 Cfr.: M. A. Asturias, El problema social del indio y otros textos, recogidos y presentados por C. Couffon, París, Centre de Recherches de l'Institut d'Etudes Hispaniques, 1971.

3 C. Couffon, «Introducción» a M. A. Asturias, El problema social del indio, ob. cit., p. 11.

4 M. A. Asturias, «Advertencia» a El problema social del indio, ed. de C. Couffon, cit., p. 17.

5 Cfr. C. Couffon, «Introducción» a M. A. Asturias. El problema social del indio, ob. cit., p. 10. 
No olvidemos que a la sazón Asturias era ya un estudiante comprometido. Su familia lo era también, y el joven había participado, como él mismo declaraba con frecuencia, en el derrocamiento del dictador Estrada Cabrera, en abril de $1920^{6}$.

$\mathrm{Su}$ «indigenismo» era, pues, un movimiento espontáneo, de reacción contra la injusticia. En ese momento Asturias veía la posibilidad de recuperación de una extensa masa humana - que representaba las dos terceras partes del país- por medio de la inmigración y la mezcla racial: el mestizaje.

A distancia de cincuenta años él mismo denunciaría su equivocación al propósito, procedente del que define «juvenil entusiasmo»:

«A la fecha las experiencias has demostrado que si se llevan inmigrantes, éstos, no sólo no se mezclan con el indio, sino muy pronto se convierten en jefes, patrones, o capataces del infeliz nativo»?

Una verdad elemental, que sólo el entusiasmo y la juventud podían ocultar y que se le presenta clara al escritor en 1973, cuando hace la declaración citada. Pero ya en su tesis Asturias no se muestra muy seguro del éxito «despertador» —digamos así- de su denuncia; su llamamiento es al amor: una posición, como se ve, dominada por el sentimiento. Y además, por más publicidad que le diera a su trabajo editándolo, ¿qué efecto concreto hubiera podido tener? Ninguno, seguramente.

A pesar de ello, Asturias no renuncia a su sueño utópico, porque de utopía se trata. Para él, mestizo, aunque perteneciente a una familia de la clase burguesa acomodada, la situación del indígena continuará siendo inquietante; como por reacción a su impotencia material para determinar cambios él dará al tema, en su obra, categoría mítica.

Siempre seguirá afirmando que el mestizaje es la solución. A distancia de decenios lo presentará como un evento mágico: «iTodo está ya lleno de comienzos» ${ }^{8}$, será la frase recurrente en Maladrón, cuando el fruto de la unión entre el blanco conquistador y la india Titil-Ic, «Eclipse de Luna». Y es un indio quien pronuncia la frase.

Ya Asturias no es el joven autor de la tesis sobre el indio, sino un hombre maduro, encaminado hacia su crepúsculo, un crepúsculo, hay que decirlo, de signo extraordinariamente positivo, que le verá en su momento creador más vigoroso - piénsese en Mulata del tal y en Clarivigilia Primaveral- y le obtendrá el Premio Nobel en 1967.

La del mestizaje es la única solución que Asturias presenta para el rescate del mundo indígena. Lo de la solidaridad humana lo contemplará el artista con relación a la clase obrera, en una dimensión económico-política, cuando la huelga contra el imperialismo, en la llamada «Trilogı bananera»: el triunfo se realizará en Los ojos de los enterrados. Es otra cosa.

6 Ver de M. A. Asturias, por ejemplo, las entrevistas con Luis López Álvarez, en Conversaciones con Miguel Angel Asturias, San José de Costa Rica, EDUCA, 1974, pp. 101-109.

7 M. A. Asturias, «Advertencia» cit., p. 18.

8 M. A. Asturias, Maladrón, Buenos Aires, Losada, 1969, p. 135. 
Parece como si el novelista se hubiese convencido de que no hay solidaridad posible, en lo concreto, hacia el indígena. Queda sólo un camino: afirmar su superioridad cultural y su unicidad, o sea mitificarlo.

El primer producto de esta orientación, en la creación artística de Asturias, lo tenemos en las Leyendas de Guatemala, allá por el año 1930. A esta altura el tema del rescate material del indígena ha desaparecido. En las Leyendas no se trata todavía de una afirmación conciente de superioridad cultural, sino de un rescate-fundación que podríamos definir «anímico» del mundo indígena. Luego la temática irá ampliándose.

El indigenismo de Asturias experimenta, pues, una evolución original, y para nosotros interesante. No se trata de una renuncia a la responsabilidad, sino de una forma particular de «compromiso». El artista, sintiéndose impotente, y probablemente sin preparación ideológica adecuada para influir en cambios concretos, opta por enaltecer la dignidad de los humildes y ofendidos, a través de la celebración de su peculiar manera de entender el mundo y de su cultura, la antigua, se entiende, la de los maya-quiché, tan profundamente presente hasta en la actualidad, a pesar de la desgracia.

El primer encuentro concreto con esta cultura, determinada desde el punto de vista de la asunción conciente de la misma, se realiza en Francia, cuando el joven Asturias empieza a frecuentar las clases sobre mitos y religiones de la Mesoamérica, que dicta en la Sorbona Georges Raynaud. Se trata de un verdadero descubrimiento para el joven, que le permite superar el consabido complejo de inferioridad que por entonces parecía inevitable en el latinoamericano frente al europeo. La traducción del Popol-Vuh, del francés al castellano, bajo la guía de tan riguroso maestro ${ }^{9}$, lo pondrá en contacto con el «milagro», la maravilla de la creación del mundo mesoamericano, su esplendorosa unicidad.

En el ámbito creativo, hemos dicho, el primer producto de la nueva orientación son las Leyendas de Guatemala, en vilo entre el mundo mestizo y el mundo indio; las mismas que despertaron el entusiasmo de Paul Valéry por su carácter novedoso ${ }^{10}$, y seguramente por su acento, para el francés, atractivamente exótico. Estaba muy lejos, por ese entonces, Valéry, de sospechar cuánta adhesión afectiva había a ese mundo de parte del autor y qué significaban esas narraciones en su programa de rescate del indígena.

No me detendré a examinar las Leyendas; vale la pena, sin embargo, llamar la atención sobre una, «Los brujos de la tormenta primaveral» — anunció claro del que será, decenios después, el poema Clarivigilia Primaveral_, para tener la medida exacta de la adhesión de Asturias al mundo indígena, ya no visto en su miseria y para formular una protesta contra ella, como seguirá haciendo en algunos poemas — véase Sien de Alondra-, sino para interpretar la extraordinaria sugestión de su cosmogonía, el misterio de la creación, que si mucho le debe al Popol-Vuh en su arranque inspirativo, alcanza una indiscutible originalidad por

9 M. A. Asturias, en L. López Álvarez, Conversaciones con M. A. Asturias, cit. p. 76.

10 P. Valéry, «Carta de Paul Valéry a Francis de Miomandre», en M. A. Asturias, Leyendas de Guatemala, Buenos Aires, Editorial Pleamar, 1948. 
concepción, imágenes y sonido. En una prosa llena de humores vitales, presenciamos el majestuoso comienzo del mundo americano:

«Los ríos navegables, los hijos de las lluvias, los del comercio carnal con el mar, andaban en la superficie de la tierra y dentro de la tierra en lucha con las montañas, los volcanes y los llanos engañadores que se paseaban por el suelo comido de abismos, como balsas móviles. Encuentros estelares en el tacto del barro, en el fondo del cielo, que fijaba la mirada cegatona de los crisopacios, en el sosegado desorden de las aguas errantes sobre lechos invisibles de arenas esponjosas, y en el berrinche de los pedernales enfurecidos por el rayo» ${ }^{11}$.

Es aquí donde empieza el «realismo mágico» de Asturias, como asunción íntima de una cultura y una mentalidad, que da una dimensión nueva a la realidad. El Señor Presidente, la novela que dará fama y renombre al hasta entonces oscuro narrador, es, a pesar de la novedad que presenta siempre he sostenido que con ella empieza la «nueva novela» hispanoamericana, sobre todo en el manejo del tiempo y el recurso a lo onírico, un paréntesis dentro del clima mágico con el que Asturias interpreta la realidad. A distancia de años el escritor afirmará:

«... el realismo mágico [...] es un relato que va en dos planos: un plano de la realidad y un plano de lo irreal. Pero el indígena cuando habla de lo irreal, da tal cantidad de detalles de su sueño, de su alucinación, que todos esos detalles convergen para hacer más real el sueño y la alucinación que la realidad misma. Es decir que no puede hablarse de este realismo mágico sin pensar en la mentalidad primitiva del indio, en su manera de apreciar las cosas de la naturaleza y en sus profundas creencias ancestrales» ${ }^{12}$.

Es una manera para afirmar la superioridad del indio. La naturaleza cobra vida en su particular visión, es real y mágica al mismo tiempo. Miguel Angel Asturias interpreta desde adentro esta extraordinaria dimensión del mundo indígena. Nadie mejor calificado que él, si en una entrevista declaraba que, por ser fruto de una mezcla racial, la parte india luchaba dentro de su espíritu con la parte hispánica ${ }^{13}$.

La dimensión mágica del mundo indígena va conquistando progresivamente al artista. El entusiasmo de Asturias se dirige claramente hacia un mundo que se le presenta como irrepetible, mundo de "golosina» ${ }^{14}$, de "encantamiento y esplendor ${ }^{15}$, una suerte de paraíso perdido; perdido y reconquistado por él y vuelto a la vida, donde la magia es «otra claridad: otra luz alumbrando el universo de dentro a fuera» ${ }^{16}$, donde existe un intenso movimiento de las cosas, que «despiertan solas, y solas existen aisladas y en relación con todo lo que las rodea» ${ }^{17}$.

11 M. A. Asturias, Leyendas de Guatemala, ob. cit., p. 72.

12 M. A. Asturias, en L. López Álvarez, Conversaciones con M. A. Asturias, ob. cit., p. 166.

13 Ibid., p. 163.

14 M. A. Asturias, Maladión, ob. cit., p. 23.

15 M. A. Asturias, El espejo de Lida Sal, México, Siglo XXI, 1967, p. 3.

16 M. A. Asturias, en L. López Álvarez, Conversaciones con M. A. Asturias, ob. cit., p. 166.

17 Ibid, p. 168 
La protesta es implícita: ¿cómo justificar el menosprecio, el abandono, la aniquilación de un mundo tan extraordinario, de una humanidad de tanta riqueza espiritual? La novela está en la formulación: a través de la mitificación de lo indígena Miguel Angel Asturias reivindica orgullosamente la superioridad de la que ya podemos llamar con toda justificación «su gente». El indio perderá su aspecto dramático, negativo; no se tratará nunca, en Asturias, de trágicos mascarones, como nos lo depara Jorge Icaza, por ejemplo en Huasipungo, ni de personajes donde no se distingue la diferencia de raza y cultura. En un libro publicado en pleno exilio auropeo, El espejo de Lida Sal, el narrador llegará a dar al indio de su país una categoría de «alma del paisaje», si así se puede decir, y de eternidad:

«Naturales, lógicos existentes y sin embargo, habitantes de mundos de otras categorías. Los indios de Guatemala son como piezas de imaginería, bordados, esculpidos, pintados, recamados, mayas sobrevivientes de soles pretéritos, no de este sol en movimiento. Van y vienen por los caminos de Guatemala, con no se sabe qué de inmortales» ${ }^{18}$.

Así presentados, vistos a través de una nostalgia que los mitifica más eficaz es la protesta contra su condición actual.

Asturias no se limita, sin embargo, a esto. Su «indigenismo», presenta múltiples facetas. En Hombres de maíz, por ejemplo, la dimensión mítica domina. La logra el escritor acudiendo a elementos populares de honda raíz indígena, como el mito de la busca de la esposa que abandona al marido, fuga constante de lo femenino ante lo masculino, como explica el mismo escritor ${ }^{19}$; o se trata del ciego Goyo Yic que, sin haber nunca visto a su mujer, una vez que ésta le deja recobra la vista, pero sin utilidad alguna para encontrarla, pues de ella recuerda sólo la voz. Es una dimensión interior del mundo indígena, como lo es el «nahualismo», creencia — según explica Asturias - que tiene el indígena de que, el nacer, con él aparece un animal que le protege: sea un pájaro, una serpiente, un puma, un conejo» ${ }^{20}$.

Sobre consejas, relatos y mitos de raíz indígena construye Asturias también Mulata de tal: la mujer-demonio, la tentación del diablo del maíz, Tazol, un mundo inquietante de demonios terrígenas que luchan y pierden contra el demonio cristiano, enanos y gigantones, transformaciones mágicas, ciudades donde la magia reina soberana. Invención original del artista, sobre un fondo popular, pero demostración siempre de una «diversidad» indígena convincente, una «otredad» que se afirma por su dimensión interior, frente a la constante falta de espesor de los personajes que no pertenecen al mundo indígena.

¿Quién se maravilla ya de que el Gaspar Ilóm, en Hombres de maíz, oiga la voz de la tierra quejándose por los estragos de los maiceros; o que el señor Nicho Aquino se transforme en coyote, su náhual; o también que María Tecun, su esposa, sea al mismo tiempo montaña y mujer viva y que todo ande en un plano mágico, real-irreal, alucinante? Es así como

18 M. A. Asturias, El espejo de Lida Sal, ob. cit., p. 4.

19 M. A. Asturias, en L. López Álvarez, Conversaciones con M. A. Asturias, ob. cit., p. 164.

20 Ibid., p. 165. 
«El señor Nicho navegaba en el mar junto a María Tecún, tal como era, un pobre ser humano, y al mismo tiempo andaba en forma de coyote por la cumbre de María Tecún, acompañando al Curandero-Venado de las Siete-Rozas» ${ }^{21}$.

Acudiendo a los temas populares, a los mitos del mundo indígena, Miguel Angel Asturias logra difundir una imagen extraordinariamente sugestiva del mundo indio. No falta tampoco el enjuiciamiento del acontecer histórico. En Maladrón, que significativamente lleva como subtítulo «Epopeya de los Andes Verdes», pasado ya completamente a la parte indígena, Asturias nos presenta el choque entre dos concepciones del mundo y de la guerra, la mágica indígena y la racional europea. Los «seres de injuria» ${ }^{22}$ venidos del mar, son presentados como los destructores del mundo feliz, de un mundo que es «resiembra de lo bello, flores sean dichas, de lo dulce, frutas sean dichas, dicha sea todo» ${ }^{23}$; sitio del milagro, «nube terrenal en que nace el maíz» ${ }^{24}$.

«iFábula verdad son estas Indias, islas y lierra firme en que estamos!» ${ }^{25}$, exclamará uno de los españoles conquistadores. Celebrar la maravilla del mundo americano significa denunciar una suerte de sacrilegio cometido por sus destructores. $\mathrm{Al}$ indigenismo de Asturias la belleza de la naturaleza presta argumento. Con mororidad el artista describe al atmósfera única del mundo indígena y abunda en colores y aromas:

«... clima de pluma de paloma entre palmeras con sombra de pelo de mujer, brisa marina bajo el abanico de los cocales y a la mano, por el suelo, los cocos, agua y carne de hostia, y las piñas, oro dulce, oro con perfume y las anonas, plata de sueño, y los plátanos rosados de carne de niño vegetal, y los mangos confitados en trementina, y la caña de azúcar, y los zapotes rojos, y las granadillas, y las tunas, y los nances, y las cerezas, y los membrillos, y los caimitos, y las guayabas, los duraznos, los matasanos y las piñuelas...» ${ }^{26}$.

Frente al raudal milagroso la profanación:

«Abajo, en la planicie conquistada, los españoles celebran la victoria, triunfo que pronto será bostezo y hambre de seres extraños que deambularán entre las casas vacías, las poblaciones desiertas, las sementeras quemadas, los árboles desnudos» ${ }^{27}$.

Profanación es también, en El Papa verde, segunda novela de la trilogía del banano, el éxodo de los indígenas de sus tierras, impuesto por la «Platanera». Pueblos enteros se desplazan, en una noche de pesadilla. Asturias denuncia el atropello con eficaz insistencia, el complot del capital y el poder político, la tragedia del mundo indígena desposeído de su tierra y con ella de su identidad:

21 M. A. Asturias, Hombres de maiz, Buenos Aires, Losada, 1949, p. 276.

22 M. A. Asturias, Maladrón, ob. cit., p. 24.

23 Ibid., p. 11.

24 Ibidem.

25 Ibid., pp. 30-31.

26 Ibid., pp. 31-32.

27 Ibid, p. 28. 
«... Se oía que andaban pueblos enteros. El pegarse de la planta del pie desnudo en la tierra caliente. Pegarse y despegarse. Ruido de hojas que tras tostarse al sol se han humedecido con la noche $[\ldots] \gg{ }^{28}$.

«Se le calcinaban los pies aterronados. Pedazos de tierra que se va. Pies desnudos. Interminables filas. Pies de campesinos arrancados de sus cultivos. Imagen de la tierra que se va, que emigra, que deja escapar pedazos de su gleba buena, caída de los astros, para que no permanezca donde ha sido privada de sus raíces. No tenían caras. No tenían manos. No tenían cuerpos. Sólo pies, pies, pies, pies para buscar rutas, repechos, desmontes por donde escapar. Las mismas caras, las mismas manos, los mismos cuerpos sobre pies para escapar, pies, pies, sólo pies, pedazos de tierras con dedos, terrones de barro con dedos, pies, pies, sólo pies, pies, pies, pies... Se les ve donde van, ya no están en sitio alguno, van, marchan, sin hacer ruido, sin levantar polvo, marchan, marchan, marchan, brasa y humo las viviendas, y el descuaje de los bosques semisumergidos en el agua, humedad jabonosa donde sólo impera el zompopo, la abeja negra, nubes de insectos, guacamayos y monos» ${ }^{29}$.

Hombre y tierra son una sola unidad. En el dolor silencioso del indígena percibimos el del desterrado artista: «Dulce es la tierra donde uno nace. No tiene precio. Toda la demás es amarga» ${ }^{30}$.

Más tarde, en Los ojos de los enterrados, de tan intensa participación contra el monopolio generador de la dictadura y la desesperada condición guatemalteca, Asturias vuelve a tratar de mitos y «brujerías», entendiéndolos como expresión especialísima de la espiritualidad del mundo indígena. Pero es en Maladrón donde el tema indigenista cobra una dimensión histórico-mítica, y en este sentido su mayor resalte, en la representación del choque de mundos distintos, que ha provocado, con la derrota del indio, su injustificada marginación.

Permanece intacta la naturaleza en su belleza irrepetible, memoria del mundo feliz, testimonio de su dignidad y grandeza. La condición humana del indígena destaca más su nota negativa en lo positivo del mundo que lo rodea.

La gran creación «indigenista» de Miguel Angel Asturias es, sin embargo, Mulata de tal, su última gran novela. El Alhajadito, en efecto, es un libro interesante y compositor, de dudosa construcción, y además no entra en nuestro tema. Viernes de dolores, postrera publicación del artista, vuelve al período de las luchas políticas estudiantiles, y tampoco tiene que ver con nuestro asunto.

Con Mulata de tal el narrador guatemalteco se sumerge en una «indianidad» total: al mismo tiempo que elabora una realidad mágica, en un gigantesco fresco, un lienzo sin fin, de la Guatemala indígena, ahonda en una dimensión interior de extraordinarios matices. Compromiso y evasión se juntan en este trabajo, el uno patente en el empeño interpretativo, el otro en el transparente deleite creativo del artista.

Himno y elegía al mismo tiempo, celebración vitalista y desalentada constatación, paraíso mágico y doliente, todo confluye a formar una singular novela,

9 Ibíd., p. 81.

30 Ibid., p. 82. 
donde el narrador alcanza, en lo creativo, su cumbre, expresando, en un barroquismo original, una visión definitiva del mundo guatemalteco.

Magia y realidad, fundiéndose, construyen una representación mítica, un cuadro vivo, destinado a grabarse para siempre en la sensibilidad del lector, como ocurrió con la descripción colombiana del mundo antillano, hoy todavía imagen sugestiva de la supuesta América feliz.

Asturias da vida a una conciencia de lo inédito, a una dimensión particular que contrasta con la mentalidad europea. En Mulata de tal el mundo indígena parece alcanzar realmente esa «claridad» de que el novelista hablara, que ilumina la realidad desde adentro y le da vida ${ }^{31}$. La misma claridad que encontramos en Clarivigilia Primaveral y que, según se expresa el autor, «nace de los seres y de las cosas. Claridad interna, posibilidad de imán que nos atrae, que alumbra desde su propio ser» ${ }^{32}$.

En Mulata de tal relatos, consejas y mitos son parte integrante de la unicidad del mundo indígena guatemalteco, como lo concibe Asturias en su dimensión más profunda. Un mundo superior al europeo, también desde el punto de vista moral. Lo vemos en la aventura de Celestino Yumi, tentado por el diablo del maíz Tazol, a quien le vende su esposa por ser rico. Una riqueza estéril, pues no produce felicidad. Recuperada la Catalina Zavala, vuelta humo la descomunal riqueza, la pareja vuelve a su antiguo pueblo, Quiavicús, irreconocible y donde nadie ya los reconoce: son pobres, pero poseen la vida. Dirá Celestino, frente a la nueva condición: "La nueva vida es la vida y nada más, no hay vida mala, porque la vida en sí es lo mejor que tenemos» ${ }^{33}$.

Cashtoc, «el Grande, el Inmenso», mantiene el orden en el mundo indígena y destruye al hombre que traiciona su naturaleza y se vuelve egoísta. A través del mito, Miguel Angel Asturias impone una superior moralidad del mundo indio sobre el europeo. La «comunidad» es la perfecta realización del hombre, que si sale de ella debe ser aniquilado. Así es como el mundo de Tierrapaulita, revuelto por el pecado, distorsionado, será destruido. Cuando los demonios terrígenas, vencidos por la maldad del demonio cristiano, abandonan la ciudad a su triste destino, sobre ella caerá una suerte de destrucción atómica: «... un alud, no de nieve, de luz blanca, fuego de la familia de la lava, fuego blanco que peor que la lava volcánica, que es fuego negro, consumía, evaporaba, disolvía [...]» ${ }^{34}$. «Holocausto apocalíptico», lo ha definido Luis Harss, sobre el que desciende un enorme silencio:

«El silencio, el silencio también, callaba entre los cielos y la tierra, mientras iba pintando el día cubierto de plumas de fuego inmensas, sobre las que en estrías aún más luminosas corrían regueros de plumitas de colores que se amontonaban empujadas por quién sabe que vientos, hacia el sitio en que estuvo Tierrapaulita, y está, sólo que soterrada, $[\ldots]{ }^{35}$.

31 M. A. Asturias, en L. López Álvarez, Conversaciones con M. A. Asturias, ob. cit., p. 166.

32 Ibid., p. 168.

33 M. A. Asturias, Mulata de tal, Buenos Aires, Losada, 1963, p. 93.

34 Ibid., p. 298.

35 Ibid., p. 241. 
Como siempre, o casi siempre, la protesta de Asturias en implícita: con la conquista y la evangelización del indígena el novelista denuncia la orfandad en que los eventos históricos lo han dejado. Enalteciendo la dimensión cultural y mágica de su mundo Asturias le da dignidad permanente. El lector de sus novelas, de toda su obra, incluso su teatro, donde el personaje mítico es el Padre las Casas - véase La Audiencia de los Confines - tendrá siempre presente una categoría exaltante del indígena guatemalteco y de su mundo, y acentuará la grandeza de la injusticia. Asturias no elabora ideologías, «endiosa», según su expresión, las cosas, como es propio del artista ${ }^{36}$. No le pidamos peras al olmo: al artista pidámosle una creación valedera y una adhesión sincera a la condición del hombre. Es lo que Asturias nos ha dado y ha demostrado constantemente, junto con una gran pasión por su tierra.

36 M. A. Asturias, en L. López Álvarez, Conversaciones con M. A. Asturias, ob. cit., p. 168. 